\title{
Serial determinations of oxygen profiles in infants with respiratory distress
}

\author{
WILLIAM L. HOLMAN, ALFRED N. KRAUSS, AND PETER A. M. AULD
}

From the Perinatology Center, Department of Pediatrics, New York Hospital-Cornell University Medical College, New York

SUMMARY Serial oxygen profiles were determined for 20 newborn infants by measuring arterial tensions at low (20-40\%), intermediate (60-80\%), and high (95-100\%) levels of inspired oxygen. These points were plotted on a graph which estimated the percentage of venous admixture at any particular level of inspired oxygen. The infants' oxygen profiles were then determined. As much as $25 \%$ of venous admixture could be attributed to the presence of diffusion and distribution abnormalities in infants with hyaline membrane disease. A substantial number of infants showed increased shunting at high levels of oxygen, even in the presence of continuous distending airway pressure. It is hypothesised that a rising shunt is due to complete absorption of gas in poorly ventilated alveoli at high concentrations of inspired oxygen, resulting in the presence of atelectasis and redistribution of blood to poorly ventilated areas.

Studies of pulmonary function in neonates with prematurity and/or respiratory distress have consistently found significant alveolar-arterial oxygen gradients (Nelson et al., 1963a; Thibeault et al., 1966, 1967, 1968; Krauss and Auld, 1969; Tori et al., 1973). The alveolar-arterial oxygen gradient has been shown to persist at high alveolar oxygen concentrations (Thibeault et al., 1967; Tori et al., 1973) and in the absence of large urinary-alveolar nitrogen gradients (Krauss and Auld, 1969) or abnormal nitrogen washout curves (Tori et al., 1973). This suggests that the major cause of the gradient is cardiopulmonary shunting rather than diffusion barriers or distribution abnormalities (Farhi and Rahn, 1955; Strang and MacLeish, 1961; Davidson et al., 1972; Tori et al., 1973), although there is evidence contrary to this conclusion (Ledbetter et al., 1967).

This study was designed to estimate the percentage of cardiac output which is shunted from right to left at low, intermediate, and high concentrations of inspired oxygen, using the graphs designed by Druger et al. (1973) (Fig.). When change in estimated right-to-left shunt is plotted against inspired oxygen, an oxygen profile is created. Oxygen profiles were studied serially to assess the shunting characteristics of the neonatal lung. The oxygen profiles were also used to compare the shunting characteristics in the lungs of infants treated with positive airway presReceived 23 June 1977 sures in contrast with infants allowed to breath spontaneously.

\section{Methods and materials}

Twenty neonates ranging in weight from $940 \mathrm{~g}$ to $4500 \mathrm{~g}$ were studied, with the informed consent of their parents. All were patients in the Neonatal Intensive Care Unit at New York Hospital and all were being treated for respiratory distress, diagnosed on the basis of tachypnoea, retractions, and a need for oxygen beyond 4 hours of birth. Hyaline membrane disease was diagnosed on the basis of respiratory distress associated with ground-glass appearance of the lungs in association with air bronchograms on chest $x$-ray. Meconium aspiration was diagnosed when respiratory distress occurred in association with an over-inflated chest and meconium staining of the skin, and a chest $x$-ray characterised by bilateral coarse infiltrates. Transient tachypnoea of the newborn was diagnosed when respiratory distress was associated with rapid breathing, large chest diameter, and lack of meconium staining in an infant without the radiological finding of hyaline membrane disease or meconium aspiration.

The levels of inspired oxygen were determined with an International Biophysics Corporation Model 300 oxygen analyser which was calibrated daily with air and $100 \%$ oxygen. Continuous positive airways pressure (CPAP) was given by a bag and mask held 


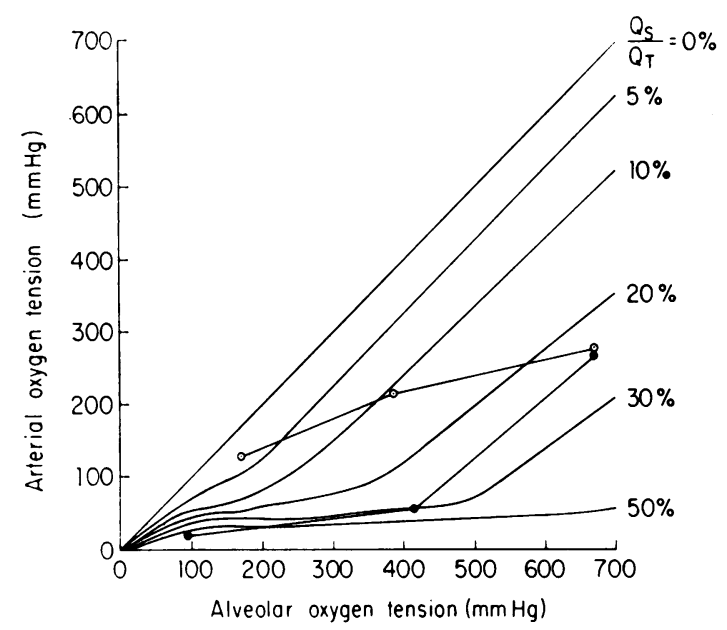

Fig. Examples of oxygen profiles, one 'positive' and the other 'negative' (see text).

securely over the infant's mouth and nose, and positive end expiratory pressure (PEEP) was administered by a Bourns respirator. Both of these pressures were held within the range of 3 to $6 \mathrm{~cm}$ $\mathrm{H}_{2} \mathrm{O}$. Several spontaneously breathing infants received oxygen from a mask held close to the face; however, Olympic Oxyhoods were used in the majority of cases to eliminate any error due to breathing around the mask. Any space existing between the arch of the neck space in the hood and the infant's neck was blocked as completely as possible. In addition, oxygen readings in the hood were taken at the patient's nose.

For this test, gas with inspired oxygen of $21-40 \%$, $60-80 \%$, and $95-100 \%$ was given to each patient. 20 minutes of breathing were allowed for equilibration and nitrogen washout before the arterial blood sample was drawn for analysis. Arterial samples were drawn either from an umbilical artery catheter, the temporal artery, or the right radial artery. The $\mathrm{pH}$, carbon dioxide tension, and oxygen tension of the sample were then immediately measured with an Instrumentation Laboratory 513 blood gas analyser calibrated with gas and blood. It was impossible to always draw samples at the same site from day to day. On any one day the samples were all drawn from the same site so that a change in arterial oxygen saturation due to a patent ductus arteriosus within one day's profile was taken into account. It has been shown that a patent ductus arteriosus may account for roughly one-tenth of the total cardiopulmonary shunt seen in respiratory distress syndrome (Murdock et al., 1970), although it has recently been suggested that the standard shunt equation may underestimate large ductal shunts (Gersony et al., 1972).

The alveolar oxygen tension was calculated with the standard alveolar air equation (Otis, 1964), assuming that alveolar carbon dioxide was equal to arterial carbon dioxide and a respiratory exchange ratio of 0.8 . The dry barometer of the day was used in all calculations. The values calculated for alveolar and arterial oxygen tensions were plotted on a graph devised by Druger et al. (1973) as modified for fetal haemoglobin. This graph allows for estimation by interpolation of the per cent shunt. The change in shunt on one day was then calculated by subtracting the per cent shunt at the highest alveolar oxygen from the per cent shunt at the lowest alveolar oxygen. Haemoglobin was maintained between 12 and $14 \mathrm{~g} / \mathrm{dl}$ by transfusion in these patients. Small variations within this range would not greatly affect the estimated shunts (Gersony et al., 1972). Similarly, small variations in arteriovenous difference for oxygen content would have small effects on the estimated shunt (Gersony et al., 1972).

\section{Results}

The data, including the change in estimated per cent shunt (oxygen profile) are presented in the Table. The graph used to estimate the percentage of shunting is shown in the Fig. with examples of a negative oxygen profile (falling line, increasing shunt as inspired oxygen increases) and a positive profile (rising line, decreasing shunt as inspired oxygen rises). No statistically significant differences were found in the percentage change in shunts (oxygen profiles) when spontaneously breathing infants with hyaline membrane disease were compared with infants receiving distending airway pressure. Spontaneously breathing infants with hyaline membrane disease had a mean increase in shunt of $5 \%$, with a standard deviation of $16 \%$. This compared with a mean decrease in shunt of $3 \%$ with a standard deviation of $16 \%$ in the group receiving continuous distending airway pressures. Wide variations of changes in percentage of shunts were observed with increasing inspired oxygen in both groups of infants, in some cases as great as $30 \%$ in either direction.

Patients showing an increasing shunt (negative profile) have higher initial arterial oxygen tensions than patients with falling shunts (positive profile). Those with positive profiles had a mean initial arterial oxygen tension of $45 \pm \mathrm{mmHg}$ compared to a mean of $67 \pm 28 \mathrm{mmHg}$ in the negative profile group. This difference was significant $(t=2.9649$, $\mathbf{P}<0.01$ ). A linear relationship between initial $\mathbf{P O}_{2}$ and oxygen profile was found. This relationship, $\mathrm{PO}_{2}=(-0.96)$ (oxygen profile) +58 , was highly significant $(r=-0.50, t=3.744, P<0.001)$. 
Table Clinical data on infants

\begin{tabular}{|c|c|c|c|c|c|c|c|}
\hline Case no. & Birthweight $(g)$ & Study age $(d)$ & $\begin{array}{l}\text { Initial arterial } \\
\mathrm{O}_{2}\left(\mathrm{~mm} \mathrm{H}_{8}\right)\end{array}$ & $\begin{array}{c}\text { Final arterial } \\
\mathrm{O}_{2}(\mathrm{mmHg})\end{array}$ & $\begin{array}{l}\text { Initial \% shunt } \\
\text { (estimate) }\end{array}$ & $\begin{array}{l}\text { Final \% shunt } \\
\text { (estimate) }\end{array}$ & $\begin{array}{l}\text { Change in estimated \% } \\
\text { shunt (oxygen profile) }\end{array}$ \\
\hline \multirow{2}{*}{\multicolumn{8}{|c|}{ Group I. Hyaline membrane disease with positive end-expiratory pressure $(P E E P)$ of $+5 \mathrm{~cm}$ of water }} \\
\hline 1 & 1400 & 0 & & & & & \\
\hline & 290 & 1 & 63 & 195 & 25 & 29 & -4 \\
\hline \multirow[t]{2}{*}{2} & 2200 & 0 & 47 & 323 & 15 & 22 & -7 \\
\hline & & 1 & 40 & 315 & 25 & 23 & +2 \\
\hline \multirow[t]{2}{*}{3} & 2300 & o & 27 & 281 & 50 & 24 & +26 \\
\hline & 1900 & 1 & 67 & 281 & 20 & 24 & -4 \\
\hline 4 & 1900 & $\begin{array}{l}0 \\
4\end{array}$ & $\begin{array}{l}67 \\
55\end{array}$ & $\begin{array}{l}272 \\
152\end{array}$ & $\begin{array}{l}22 \\
28\end{array}$ & $\begin{array}{l}25 \\
34\end{array}$ & $\begin{array}{l}-3 \\
-6\end{array}$ \\
\hline \multirow[t]{2}{*}{5} & 1920 & 0 & 16 & 156 & 20 & $\begin{array}{l}34 \\
30\end{array}$ & $\begin{array}{r}-6 \\
-10\end{array}$ \\
\hline & & 4 & 136 & 265 & 5 & 25 & -20 \\
\hline \multirow[t]{2}{*}{6} & 1021 & 3 & 65 & 245 & 10 & 27 & -17 \\
\hline & & 4 & 48 & 120 & 30 & 36 & -6 \\
\hline \multirow[t]{2}{*}{7} & 940 & 1 & 76 & 315 & 9 & 23 & -14 \\
\hline & & 2 & 39 & 245 & 50 & 27 & +23 \\
\hline \multirow{3}{*}{$\begin{array}{l}8 \\
9\end{array}$} & 2400 & 1 & 36 & 200 & 50 & 15 & +35 \\
\hline & 1840 & 1 & 37 & 318 & 50 & 22 & +28 \\
\hline & & $\begin{array}{l}2 \\
3\end{array}$ & $\begin{array}{l}32 \\
62\end{array}$ & $\begin{array}{l}270 \\
316\end{array}$ & $\begin{array}{l}50 \\
15\end{array}$ & $\begin{array}{l}25 \\
22\end{array}$ & $\begin{array}{r}+25 \\
-7\end{array}$ \\
\hline \multirow{2}{*}{$\begin{array}{l}\text { Mean } \\
\text { SD }\end{array}$} & 1769 & & 55 & 254 & 28 & 25 & +3 \\
\hline & 535 & & 27 & 64 & 16 & 5 & 16 \\
\hline \multicolumn{8}{|c|}{ Group II. Hyaline membrane disease breathing spontaneously } \\
\hline \multirow{6}{*}{$\begin{array}{r}2 \\
5 \\
8 \\
10 \\
11\end{array}$} & 2200 & 8 & 73 & 396 & 5 & 19 & -14 \\
\hline & 1900 & 4 & 179 & 396 & 5 & 15 & -10 \\
\hline & 2400 & 2 & 20 & 59 & 30 & 40 & -10 \\
\hline & 2300 & 2 & 52 & 354 & 10 & 12 & -2 \\
\hline & 2240 & 0 & 75 & 310 & 5 & 22 & -17 \\
\hline & & 7 & 60 & 291 & 5 & 24 & -19 \\
\hline \multirow{2}{*}{12} & 1470 & 2 & 59 & 337 & 8 & 13 & -5 \\
\hline & & 4 & 89 & 330 & 4 & 20 & -16 \\
\hline \multirow[t]{2}{*}{13} & 3345 & $\begin{array}{l}4 \\
7\end{array}$ & $\begin{array}{l}34 \\
69\end{array}$ & $\begin{array}{l}140 \\
326\end{array}$ & $\begin{array}{r}50 \\
6\end{array}$ & $\begin{array}{l}27 \\
22\end{array}$ & +23 \\
\hline & & 15 & 76 & $\begin{array}{l}326 \\
325\end{array}$ & 4 & 22 & $\begin{array}{l}-16 \\
-18\end{array}$ \\
\hline \multirow[t]{2}{*}{$14^{\star}$} & 2110 & 1 & 39 & 186 & 50 & 32 & +18 \\
\hline & & 8 & 68 & 222 & 11 & 29 & -18 \\
\hline 15 & 1620 & 0 & 66 & 324 & 10 & 17 & -7 \\
\hline \multirow{2}{*}{$\begin{array}{l}\text { Mean } \\
\text { SD }\end{array}$} & 2178 & & 69 & 285 & 15 & 22 & -8 \\
\hline & 537 & & 37 & 98 & 16 & 8 & 13 \\
\hline \multicolumn{8}{|c|}{ Group III. Transient tachypnoea of the newborn (spontaneous breathing) } \\
\hline \multirow{3}{*}{\multicolumn{2}{|c|}{163402}} & 2 & 72 & 107 & 21 & 28 & -7 \\
\hline & & 3 & 56 & 113 & 15 & 14 & -7 \\
\hline & & 9 & 68 & 239 & 10 & 23 & -13 \\
\hline \multirow[t]{2}{*}{17} & 3969 & 1 & 47 & 284 & 22 & 25 & -3 \\
\hline & & 2 & 83 & 223 & $\mathbf{5}$ & 30 & -25 \\
\hline $\begin{array}{l}\text { Mean } \\
\text { SD }\end{array}$ & $\begin{array}{r}3686 \\
401\end{array}$ & & 65 & 193 & 15 & 24 & -9 \\
\hline SD & 401 & & 14 & 79 & 7 & 6 & 19 \\
\hline Group IV. & Meconium aspirati & on (spontaneous & breathing) & & & & \\
\hline 18 & 4500 & 2 & 52 & 316 & 10 & 12 & -2 \\
\hline & & 3 & 55 & 415 & 15 & 19 & -4 \\
\hline 19 & 3600 & 1 & 67 & 213 & 30 & 21 & +9 \\
\hline & & 2 & 58 & 233 & 20 & 24 & -4 \\
\hline 20 & 4100 & 2 & 60 & 82 & 28 & 38 & -10 \\
\hline & & 3 & 73 & 123 & 22 & 33 & -11 \\
\hline $\begin{array}{l}\text { Mean } \\
\text { SD }\end{array}$ & $\begin{array}{r}4067 \\
451\end{array}$ & & 61 & 230 & 21 & 25 & -4 \\
\hline SD & 451 & & 8 & 122 & 8 & 10 & 7 \\
\hline
\end{tabular}

Note: Oxygen profile is calculated as the difference in estimated per cent of shunt between lowest and highest inspired oxygen concentrations. The profile is positive when the shunt decreases and negative when the shunt increases. See Fig. for examples.

\section{Discussion}

There are three causes for venous admixture. They are distribution (i.e. VA/Q) abnormalities, diffusion abnormalities, and true right-to-left shunting (West,
1970; Davidson et al., 1972; Druger et al., 1973). The contribution to the shunt-like effect of the first two factors is overcome by breathing a high concentration of inspired oxygen (West, 1970; Druger et al., 1973). Thus, the presence of positive oxygen profiles 
in infants with hyaline membrane disease indicates the existence of either distribution or diffusion abnormalities which may account for as much as $25 \%$ of the observed venous admixture at lower concentrations of inspired oxygen. These factors have previously been thought to play a less substantial role in hyaline membrane disease (Krauss and Auld, 1969; Tori et al., 1973; Corbet et al., 1974; Krauss et al., 1976).

Negative profiles should be found only if the amount of true cardiopulmonary shunting is increased at high levels of inspired oxygen. This increase in shunting at high concentrations of oxygen may be caused by the complete absorption of gases in poorly ventilated alveoli which results in atelectasis and an increased pulmonary shunt component. There is extensive evidence to support the concept of absorption atelectasis. In 1955, Dale and Rahn noted the possibility for the rapid formation of new areas of atelectasis in alveoli containing a high concentration of oxygen. Nelson et al. (1963b) proved that breathing $100 \%$ oxygen caused a decrease in the thoracic gas volume calculated in infants breathing $21 \%$ oxygen. Thibeault et al. (1967) showed that in 12 of 18 infants studied prolonged oxygen breathing caused an increase over time in the observed alveolar-arterial oxygen difference.

The existence of negative profiles would imply that a lung space which is prone to absorption atelectasis exists from day 0 to day 9 . This space may be related to such poorly ventilated lung spaces as areas of trapped pulmonary gas which disappear over time (Nelson et al., 1963b), or the area distal to an occlusion by meconium aspiration. The highly compliant airways in the lungs of preterm neonates (Burnard et al., 1965) may also contribute to the susceptibility of their lungs to resorption atelectasis through a mechanism of airway closure.

Oxygen has two other effects in the newborn infant. First, increased oxygen tensions have been shown to cause the closure of the ductus arteriosus (Kovalvík, 1963; Assali et al., 1963) in isolated in vitro animal preparations (Kovalvík, 1963; Assali et al., 1963), in vivo animal studies (Assali et al., 1963), and man (Moss et al., 1964). This is not a salient factor in the results of this study because closure of the ductus would decrease cardiopulmonary shunting at high oxygen levels, which would result in a positive oxygen profile.

Second, changes in the level of inspired oxygen have been shown to alter the vascular tone in normal man (Motley et al., 1947), adults with acute respiratory failure (Enson et al., 1964; Suter et al., 1975), and in the lamb fetus (Dawes, 1966). Reduced oxygen levels induce vasoconstriction and increased oxygen levels induce vasodilation by a direct mechanism (Dawes, 1966; Suter et al., 1975). The recent studies of Suter et al. suggest that high levels of inspired oxygen may result in redistribution of blood to poorly ventilated areas of the lung in addition to causing atelectasis (Suter et al., 1975).

These findings have important implications for present day diagnostic procedures used to evaluate infants with respiratory distress because many of these procedures include the determination of arterial oxygen tension at high concentrations of inspired oxygen (Strang and Macleish, 1961; Boston et al., 1966; Stahlman et al., 1967; Roberton et al., 1968; Duc, 1971). In 1966, Boston et al. created a system of prognostic classification for infants with respiratory distress syndrome which was based solely on the blood $\mathrm{pH}$ and the initial arterial oxygen tension determined with the infant breathing $100 \%$ oxygen. A low risk group (arterial oxygen tension $>100$ $\mathrm{mmHg}, \mathrm{pH}>7 \cdot 20$ ), and a high risk group (arterial oxygen tension $\leqslant 100 \mathrm{mmHg}, \mathrm{pH} \leqslant 7 \cdot 20$ ) were defined.

In 1967, Stahlman et al. refined this system of classification. They included the parameters of arterial oxygen tension while breathing $100 \%$ oxygen, blood $\mathrm{pH}$, birthweight, respiratory rate, and serum potassium in determining a discriminant score for the infant. The discriminant score places the infant in a class interval scheme, which in turn provides information for the prognosis. The most powerful factor in determining the discriminant score is the arterial oxygen tension measured while the patient inspired $100 \%$ oxygen. The finding of an increased shunt at high levels of inspired oxygen adds important qualifications to these classification schemes. Arterial gas tensions measured while breathing high levels of inspired oxygen may cause an overestimation of the severity of the disease which may then lead to overly aggressive treatment and an unfairly pessimistic prognosis.

Of further interest is the observation that absorption atelectasis may take place even in the presence of continuous distending airway pressures. The presence of a group of infants with decreasing shunt at high levels of inspired oxygen indicates that at least some infants with hyaline membrane disease may have significant defects in distribution, diffusion, and diffusion/perfusion ratios similar to those shown to be present in adults with severe pulmonary disease (King et al., 1974; Briscoe and King, 1974).

\section{References}

Assali, N. S., Morris, J. A., Smith, R. W., and Manson, W. A. (1963). Studies on ductus arteriosus circulation. Circulation Research, 13, 478-489.

Boston, R. W., Geller, F., and Smith, C. A. (1966). Arterial blood gas tensions and acid-base balance in the manage- 
ment of the respiratory distress syndrome. Journal of Pediatrics, 68, 74-89.

Briscoe, W. A., and King, T. K. C. (1974). Analysis of the disturbance in oxygen transfer in hypoxic lung disease. American Journal of Medicine, 57, 349-360.

Burnard, E. D., Grattan-Smith, P., Picton-Warlow, C. G., and Grauaug, A. (1965). Pulmonary insufficiency in prematurity. Australian Paediatric Journal, 1, 12-38.

Corbet, A. J. S., Ross, J. A., Beaudry, P. H., and Stern, L. (1974). Ventilation-perfusion relationships as assessed by $\mathrm{aADN}_{2}$ in hyaline membrane disease. Journal of Applied Physiology, 36, 74-81.

Dale, W. A., and Rahn, H. (1955). Ventilation of the lung during unilateral experimental atelectasis. Journal of Thoracic Surgery, 29, 458-466.

Davidson, F. F., Glazier, J. B., and Murray, J. F. (1972). The components of the alveolar-arterial oxygen tension difference in normal subjects and in patients with pneumonia and obstructive lung disease. American Journal of Medicine, 52, 754-762.

Dawes, G. S. (1966). Pulmonary circulation in the foetus and newborn. British Medical Bulletin, 22, 61-66.

Druger, G. L., Simmons, D. H., and Levy, S. E. (1973). The determination of shunt-like effects and its use in clinical practice. American Review of Respiratory Diseases, 108, 1261-1265.

Duc, G. (1971). Assessment of hypoxia in the newbornsuggestions for a practical approach. Pediatrics, 48, 469481.

Enson, Y., Giuntini, C., Lewis, M. L., Morris, T. Q., Ferrer, M. I., and Harvey, R. M. (1964). The influence of hydrogen ion concentration and hypoxia on the pulmonary circulation. Journal of Clinical Investigation, 43, 1146-1162.

Farhi, L. E., and Rahn, H. (1955). A theoretical analysis of the alveolar-arterial $\mathrm{O}_{2}$ difference with special reference to the distribution effect. Journal of Applied Physiology, 7, 699-703.

Gersony, W. M., Duc, G. V., Dell, R. B., and Sinclair, J. C. (1972). Oxygen method for calculation of right-to-left shunt: new application in presence of right-to-left shunting through the ductus arteriosus. Cardiovascular Research, 6, 423-438.

King, T. K. C., Weber, B., Okinaka, A., Friedman, S. A., Smith, J. P., and Briscoe, W. A. (1974). Oxygen transfer in catastrophic respiratory failure. Chest, 65 , Suppl., $40 S-44 S$.

Kovalvik, V. (1963). The response of the isolated ductus to oxygen and anoxia. Journal of Physiology, 169, 185-197.

Krauss, A. N., and Auld, P. A. M. (1969). Ventilationperfusion abnormalities in the premature infant: triple gradient. Pediatric Research, 3, 255-264.

Krauss, A. N., and Auld, P. A. M. (1971). Pulmonary gas trapping in premature infants. Pediatric Research, 5, 10-16.

Krauss, A. M., Klain, D. B., and Auld, P. A. M. (1976). Carbon monoxide diffusing capacity in newborn infants. Pediatric Research, 10, 771-776.

Ledbetter, M. K., Homma, T., and Farhi, L. E. (1967). Readjustment in distribution of alveolar ventilation and lung perfusion in the newborn. Pediatrics, 40, 940-945.
Moss, A. J., Emmanouilides, G. C., Adams, F. H., and Chuang, K. (1964). Response of ductus arteriosus and pulmonary and systemic arterial pressure to changes in oxygen environment of newborn infants. Pediatrics, 33, 937-944.

Motley, H. L., Cournand, A., Werko, I., Himmelstein, A., and Dresdale, D. (1947). The influence of short periods of anoxia upon pulmonary artery pressures in man. American Journal of Physiology, 150, 315-320.

Murdock, A. L., Kidd, B. S. L., Llewellyn, M. A., Reid, M. McC., and Swyer, P. R. (1970). Intrapulmonary venous admixture in the respiratory distress syndrome. Biology of the Neonate, 15, 1-7.

Nelson, N. M., Prod'hom, L. S., Cherry, R. B., Lipsitz, P. J., and Smith, C. A. (1963a). Pulmonary function in the newborn infant: the alveolar-arterial oxygen gradient. Journal of Applied Physiology, 18, 534-538.

Nelson, N. M., Prod'hom, L. S., Cherry, R. B., Lipsitz, P. J., and Smith, C. A. (1963b). Pulmonary function in the newborn infant. V. Trapped gas in the normal infant's lung. Journal of Clinical Investigation, 42, 1850-1857.

Otis, A. B. (1964). Quantitative relationships in steady-state gas exchange. Handbook of Physiology, Section 3. Respiration, Vol. 1, pp. 681-698. American Physiological Society, Washington, D.C.

Roberton, N. R. C., Gupta, J. M., Dahlenburg, G. W., and Tizard, J. P. M. (1968). Oxygen therapy for the newborn. Lancet, 1, 1323-1329.

Stahlman, M. T., Battersby, E. J., Shepard, F. M., and Blankenship, W. J. (1967). Prognosis in hyaline membrane disease: use of a linear discriminant. New England Journal of Medicine, 276, 303-309.

Strang, L. B., and Macleish, M. H. (1961). Ventilatory failure and right-to-left shunt in newborn infants with respiratory distress. Pediatrics, 28, 17-27.

Suter, P. M., Fairley, H. B., and Schlobohm, R. M. (1975). Shunt, lung volume, and perfusion during short periods of ventilation with oxygen. Anesthesiology, 43, 617-627.

Thibeault, D. W., Clutario, B., and Auld, P. A. M. (1966). Arterial oxygen tension in premature infants. Journal of Pediatrics, 69, 449-451.

Thibeault, D. W., Poblete, E., and Auld, P. A. M. (1967). Alveolar-arterial oxygen difference in premature infants breathing 100 per cent oxygen. Journal of Pediatrics, 71, 814-824.

Thibeault, D. W., Poblete, E., and Auld, P. A. M. (1968). Alveolar-arterial oxygen and carbon dioxide differences and their relation to lung volume in the newborn. Pediatrics, 41, 574-587.

Tori, C. A., Krauss, A. N., and Auld, P. A. M. (1973). Serial studies of lung volume and VA/Q in hyaline membrane disease. Pediatric Research, 7, 82-88.

West, J. B. (1970). Ventilation/Blood Flow and Gas Exchange, 2nd ed., p. 100. Blackwell, Oxford.

Correspondence to Dr A. N. Krauss, Perinatology Center, The New York Hospital, 525 East 68th Street, New York, NY 10021, USA. 